\title{
Anterior to psoas fusion of the lumbar spine
}

\author{
Cristian Gragnaniello, M.D., Ph.D. and Kevin A. Seex, M.D., FRACS \\ Department of Neurosurgery, Macquarie University, Sydney, NSW, Australia
}

\begin{abstract}
Lateral interbody cages have proven useful in lumbar fusion surgery. Spanning both lateral cortical rims while sparing the anterior longitudinal ligament, they restore disc height, improve coronal balance and add stability. The standard approach to their insertion is 90 degrees lateral transpsoas which is bloodless compared to other techniques of interbody cage insertion but requires neuro-monitoring and at L4/5 can be difficult because of iliac crest obstruction or an anterior plexus position. The oblique muscle-splitting approach with the patient in a lateral position, remains retroperitoneal, and on the left side enters the disc space through a window between psoas and the common iliac vein. Reports of this approach are few and none previously have described how to use the large lateral-type cages so effective at restoring spinal alignment. In this video we demonstrate our technique of anterior to psoas fusion of the lumbar spine with a retroperitoneal approach and gentle retraction of the psoas muscle.
\end{abstract}

The video can be found here: http://youtu.be/OS2vNcX9JMA.

(http://thejns.org/doi/abs/10.3171/2013.V2.FOCUS13207)

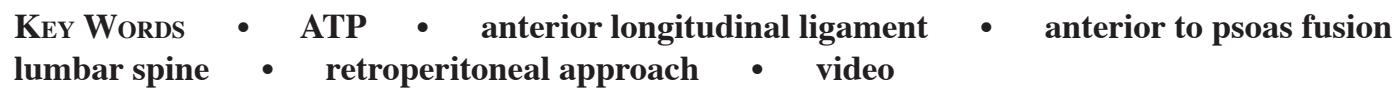

Manuscript submitted May 1, 2013.

Accepted May 30, 2013.

Please include this information when citing this paper: DOI: 10.3171/2013.V2.FOCUS13207.

Address correspondence to: Cristian Gragnaniello, M.D., Ph.D., Macquarie University, Sydney NSW 2109, Australia. email: cristian. neuro@gmail.com. 